\title{
Visual working memory deficits in undergraduates with a history of mild traumatic brain injury
}

\author{
Hector Arciniega ${ }^{1} \cdot$ Alexandrea Kilgore-Gomez $^{1} \cdot$ Alison Harris $^{2} \cdot$ Dwight J. Peterson $^{3} \cdot$ Jaclyn McBride $^{1} \cdot$ Emily Fox $^{1}$. \\ Marian E. Berryhill ${ }^{1}$
}

Published online: 19 June 2019

(C) The Psychonomic Society, Inc. 2019

\begin{abstract}
We investigated whether a history of mild traumatic brain injury (mTBI), or concussion, has any effect on visual working memory (WM) performance. In most cases, cognitive performance is thought to return to premorbid levels soon after injury, without further medical intervention. We tested this assumption in undergraduates, among whom a history of mTBI is prevalent. Notably, participants with a history of mTBI performed worse than their colleagues with no such history. Experiment 1 was based on a change detection paradigm in which we manipulated visual WM set size from one to three items, which revealed a significant deficit at set size 3. In Experiment 2 we investigated whether feedback could rescue WM performance in the mTBI group, and found that it failed. In Experiment 3 we manipulated WM maintenance duration (set size 3, 500-1,500 ms) to investigate a maintenance-related deficit. Across all durations, the mTBI group was impaired. In Experiment 4 we tested whether retrieval demands contributed to WM deficits and showed a consistent deficit across recognition and recall probes. In short, even years after an mTBI, undergraduates perform differently on visual WM tasks than their peers with no such history. Given the prevalence of mTBI, these data may benefit other researchers who see high variability in their data. Clearly, further studies will be needed to determine the breadth of the cognitive deficits in those with a history of mTBI and to identify relevant factors that contribute to positive cognitive outcomes.
\end{abstract}

Keywords Visual working memory $\cdot$ Chronic mTBI $\cdot$ Mild TBI $\cdot$ Concussion

For some years we have puzzled over the low working memory (WM) performance in some undergraduate participants. In search of an underlying cause, we noted frequent anecdotal reports of ski accidents, horseback falls, cheerleading catastrophes, and other stories of concussion, or mild traumatic brain injury (mTBI). In the United States, TBI causes 235,000 hospitalizations annually (Cameron, Marshall, Sturdivant, \& Lincoln, 2012; Corrigan, Selassie, \& Orman, 2010; Larrabee,

Hector Arciniega

harciniega@unr.edu

1 Department of Psychology, Program in Cognitive and Brain Sciences, Program in Integrative Neuroscience, University of Nevada, Reno, NV, USA

2 Department of Psychology, Claremont-McKenna College, Claremont, CA, USA

3 Department of Psychology, Concordia College, Moorhead, MN, USA
2012; Taylor, Greenspan, Xu, \& Kresnow, 2015), with > 85\% considered mild (Bazarian et al., 2005; Faul, Xu, Wald, \& Coronado, 2010). Barring the development of postconcussive syndrome, recovery is assumed to occur within a few months (Cooper et al., 2015). Early recovery reveals deficits in processing speed (De Monte \& Geffen, 2005; Shumskaya, Andriessen, Norris, \& Vos, 2012), attention (Catale, Marique, Closset, \& Meulemans, 2008; Konrad et al., 2011; Mayer et al., 2012), and episodic memory (Wammes, Good, \& Fernandes, 2017), and few have assessed cognitive performance in the chronic mTBI population, who are more than 3 months postinjury. In the chronic mTBI population, behavioral deficits are reported in a majority of participants (McInnes, Friesen, MacKenzie, Westwood, \& Boe, 2017), accompanied by neural differences (Eierud et al., 2014; Ham et al., 2014; Pan et al., 2016; Sharp \& Ham, 2011; Sharp, Scott, \& Leech, 2014; Shenton et al., 2012; Tate, Shenton, \& Bigler, 2012) detectible even years after an mTBI (Bajaj, Dailey, Rosso, Rauch, \& Killgore, 2018; Dall'Acqua et al., 2017). 
Why might we see effects of a history of mTBI on WM? WM engages broad frontoparietal networks that are vulnerable to heterogeneous impacts. Thus, across individuals, diverse injuries could lead to behavioral deficits that affect WM. Yet others investigating this issue have reported mixed results. For instance, one earlier meta-analysis reported no residual deficits in WM after the acute stage of mTBI ( $>7$ days postinjury; Belanger \& Vanderploeg, 2005); others found WM deficits exclusively in those with postconcussive syndrome, but not in the chronic mTBI sample (Dean \& Sterr, 2013), whereas others reported low WM accuracy accompanied by event-related potential differences (Gosselin et al., 2012; Hudac, Cortesa, Ledwidge, \& Molfese, 2018) or slightly greater proactive interference (Vanderploeg, Curtiss, \& Belanger, 2005). Thus, in addition to the heterogeneity of injuries, there are data reporting heterogeneous behavioral effects.

To be clear, the students we tested fell into the chronic mTBI category, because their injuries were $>3$ months before their participation (e.g., Fino et al., 2018; Goetzl et al., 2019; Lotan et al., 2018; McNerney et al., 2019). Furthermore, these undergraduates reported no sustained symptoms (e.g., headache, mental fog, etc.) that could be attributed to the mTBI itself. In other words, the only factor that distinguished the groups we tested was that one group reported having had an mTBI; thus, we use the term "history of mTBI" to characterize our participants. With regard to our questions, it is important to note that a history of mTBI is high in our undergraduates. In one 400-level course, $31 \%$ reported an mTBI, as did $37 \%$ of our Disability Resource Center clients. We conducted these experiments to test whether undergraduates with or without a history of mTBI were impaired on simple change detection WM tasks, and consequently, whether we should continue to include them in our ongoing studies of "neurotypical" participants. Across four behavioral experiments, we observed a consistent pattern: Participants with a history of mTBI performed worse at the group level than did those without a history of mTBI. These data are available at https://wolfweb. unr.edu/ mberryhill/, and we note that none of the following experiments were preregistered.

\section{Experiment 1}

\section{Materials and method}

Participants Undergraduates participated in groups of those with self-reported mTBI or controls (see Table 1 for demographics). All participants were right-handed throughout all experiments. In this and all other experiments, participants reported, in written format, whether they had a history of mTBI, how many they had had, and when the injury or injuries took place. University of Nevada, Reno's, institutional review board approved all protocols. Participants provided written consent and received their choice of $\$ 15 / \mathrm{h}$ or bonus credit.
Apparatus The task was presented on a 19-in. NEC MultiSync CRT monitor $(75 \mathrm{~Hz}, 1,024 \times 768)$ in MATLAB (The MathWorks, Natick, MA) with the Psychophysics Toolbox 3.0 extension (Brainard, 1997; Pelli, 1997), using a Mac mini 2.5-GHz dual-core Intel Core i5.

Stimulus and procedure In the change detection visual WM task (Fukuda, Awh, \& Vogel, 2010; Ikkai, McCollough, \& Vogel, 2010; Luck \& Vogel, 2013; Luria, Balaban, Awh, \& Vogel, 2016; McCollough, Machizawa, \& Vogel, 2007; Vogel $\&$ Machizawa, 2004), one to three colored squares $\left(0.7^{\circ} \times 0.7^{\circ}\right)$ were presented, chosen from a set of seven colors (cyan, white, red, blue, yellow, green, and magenta); see Fig. 1a. Trials began with a fixation cross $\left(0.4^{\circ} \times 0.4^{\circ}, 300 \mathrm{~ms}\right)$, followed by a left or right white arrowhead $\left(2.1^{\circ} \times 0.4^{\circ}, 200 \mathrm{~ms}\right)$ cueing the hemifield to covertly attend. After a delay $(300-400 \mathrm{~ms})$, the stimuli were presented $(100 \mathrm{~ms})$ in two rectangular areas $\left(7.1^{\circ} \times\right.$ $\left.12.2^{\circ}\right) 4.6^{\circ}$ from fixation. After a delay $(900 \mathrm{~ms})$, the probe appeared ( $3 \mathrm{~s})$. Participants indicated whether the stimulus and probe item matched ("o" key; 50\%) or not ("n" key). These self-paced trials included three breaks. Before testing, participants completed 24 practice trials. There were 576 trials, or 192 trials per set size (one to three items). Participants were instructed to maintain fixation, and eye movements were monitored by HD-EEG. The primary performance measure was WM capacity: $K=$ Set size * (Hit rate - False alarm rate) (Cowan, 2001; Pashler, 1988). The median correct reaction time was also recorded. Four controls performed $2+$ standard deviations below the mean and were removed.

\section{Results}

All $K$ values were subjected to a mixed-model analysis of variance (ANOVA) with the factors set size (1-3) and group (control, mTBI). Violations of sphericity were GreenhouseGeisser-corrected throughout. We found significant main effects of set size $\left[F(2,64)=582.61, p<.001, \eta_{\mathrm{p}}{ }^{2}=.95\right]$ and group $\left[F(1,32)=4.47, p=.042, \eta_{\mathrm{p}}{ }^{2}=.12\right]$, as well as a significant Set Size $\times$ Group interaction $[F(2,64)=3.74, p$ $\left.=.03, \eta_{\mathrm{p}}{ }^{2}=.1\right]$. Pairwise tests revealed that mTBI impairment emerged at set size $3(p<.04)$, but not at set size $1(p=.3)$ or 2 $(p=.07)$; see Fig. 1b. Reaction times slowed as set size increased $\left[F(1.5,47.94)=55.2, p<.00001, \eta_{\mathrm{p}}{ }^{2}=.64\right]$, and did so comparably across groups $\left[F(1,31)=3.2, p=.08, \eta_{\mathrm{p}}{ }^{2}=.1\right]$.

\section{Experiment 2}

Having observed a significant deficit in the mTBI group at set size 3 , we considered the possibility of motivation differences across groups (Ransom et al., 2016), by replicating Experiment 1 with the addition of feedback. Our rationale was that feedback might improve motivation (Miranda \& 
Table 1 Demographics across experiments

\begin{tabular}{|c|c|c|c|c|c|c|}
\hline Exp & Age $(S D)$ & $\#(\# \mathrm{~F})$ & \# TBI $(S D)$ & Range \# & Time $(S D)$ & Range Time \\
\hline 1 & $\begin{array}{l}23.83(4.0) \\
22.80(3.5)\end{array}$ & $\begin{array}{l}18(6) \\
20(8)\end{array}$ & $1.61(1.46)$ & $1-6$ & $5.60(4.80)$ & $9 \mathrm{mo}-17 \mathrm{y}$ \\
\hline 2 & $\begin{array}{l}23.44(3.5) \\
23.52(2.5)\end{array}$ & $\begin{array}{l}25(8) \\
25(15)\end{array}$ & $1.84(1.17)$ & $1-5$ & $5.61(4.11)$ & $1 \mathrm{y}-15 \mathrm{y}$ \\
\hline 3 & $\begin{array}{l}21.71(3.8) \\
21.80(4.2)\end{array}$ & $\begin{array}{l}21(10) \\
21(14)\end{array}$ & $2.14(1.62)$ & $1-7$ & 3.79 (4.09) & $4 \mathrm{mo}-9.5 \mathrm{y}$ \\
\hline 4 & $\begin{array}{l}20.77(2.1) \\
22.40(3.5)\end{array}$ & $\begin{array}{l}22(15) \\
22(15)\end{array}$ & $2.32(2.01)$ & $1-10$ & $4.33(3.08)$ & $5 \mathrm{mo}-12.8 \mathrm{y}$ \\
\hline
\end{tabular}

The top row of each experiment includes the data from those with a history of mTBI, and the second row reflects the control population data. The mean number of mTBIs and the time (in years) since the last mTBI per experiment are compiled. \#, number; Exp, experiment; F, female; mo, months; SD, standard deviation; y, years

Palmer, 2014) and decrease distractibility (Adam \& Vogel, 2017) in the mTBI group.

\section{Method}

Participants Again, our mTBI participants provided written self-reports indicating whether they had a history of mTBI, how many mTBIs, and when the injury or injuries took place. All new undergraduates participated (see Table 1).

Protocol Trials were presented in two counterbalanced blocks. One half $(N=288)$ were identical to the trials in Experiment 1, and the other half included visually presented feedback after each trial, indicating "correct" or "incorrect"; see Fig. 1a.

\section{Results}

Behavioral results Participants' $K$ measurements were subjected to a mixed-model ANOVA with the factors set size (1-3), feedback (feedback, no feedback), and group (control, mTBI). $K$ values increased with set size $[F(2,71.17)=$ $\left.1,901.82, p=.00001, \eta_{\mathrm{p}}{ }^{2}=.975\right]$, and the mTBI group was significantly impaired $\left[F(1,48)=6.4, p=.015, \eta_{\mathrm{p}}^{2}=.12\right]$. Again, a significant Set Size $\times$ Group interaction $[F(1.23$, $\left.71.17)=6.28, p=.01, \eta_{\mathrm{p}}{ }^{2}=.116\right]$ emerged at set size 3 , regardless of feedback (with feedback, $p=.01$; without feedback, $p=.02$ ); see Fig. 1c. The feedback thus had no effect $(F<1$, n.s.), and no other interactions reached significance (all $p \mathrm{~s}>.5$ ). Reaction time data showed no group differences $\left[F(1,48)=0.3, p=.6, \eta_{\mathrm{p}}{ }^{2}=.5\right]$ but revealed slowing with increased set size $[F(1.2,60.5)=50.62, p<$ $\left..0001, \eta_{\mathrm{p}}^{2}=.5\right]$.

\section{Experiment 3}

Feedback failed to rescue mTBI performance, suggesting that overall motivation level could not fully account for the set size
3 deficit. Given that performance was not significantly different at set sizes of 1 or 2 , we suspected that encoding was relatively well preserved. We next varied maintenance delay durations, to test whether maintenance was disturbed after a history of mTBI, which would lead to greater effects at longer delays.

\section{Materials and method}

Participants We tested 42 participants (see Table 1). Five of the participants with a history of mTBI who had participated in Experiment 2 also participated in Experiment 3. Here we included data collection regarding mTBI etiology and whether participants had experienced any loss of consciousness (LOC). In all, 11 of the mTBI participants reported no LOC, and ten reported LOC $(M=5.47 \mathrm{~min}, S D=9.04$, range $=1-30$ min). All mTBIs were closed-head injuries: 12 were sportsrelated, six falls/accidents, one blast, one hit by a car, and one participants did not answer.

Procedure There were three changes: Only set size 3 was included in this experiment, delay durations of 500,900 , and $1,500 \mathrm{~ms}$ were pseudorandomized, and participants completed three sessions.

\section{Results}

All $K$ values were subjected to a mixed-model ANOVA including the factors delay $(500,900,1,500 \mathrm{~ms})$ and group (control, mTBI). There was a main effect of delay $[F(1.48$, $\left.59.43)=10.31, p=.001, \eta_{\mathrm{p}}{ }^{2}=.205\right]$ with lower capacity at $500 \mathrm{~ms}$ than at either $900 \mathrm{~ms}(p=.003)$ or $1,500 \mathrm{~ms}(p=.002)$. Again, the mTBI group was impaired $[F(1,40)=8.78, p=$ $\left..005, \eta_{\mathrm{p}}^{2}=.18\right]$; see Fig. 1d. However, no interactions approached significance (all $p \mathrm{~s}>.77$ ). Reaction times showed no significant main effect of group $\left[F(1,40)=3.5, p=.07, \eta_{\mathrm{p}}{ }^{2}\right.$ $=.08]$ and slowed with increased delays $[F(1.6,64.2)=20.51$, $\left.p<.000001, \eta_{\mathrm{p}}^{2}=.34\right]$. 


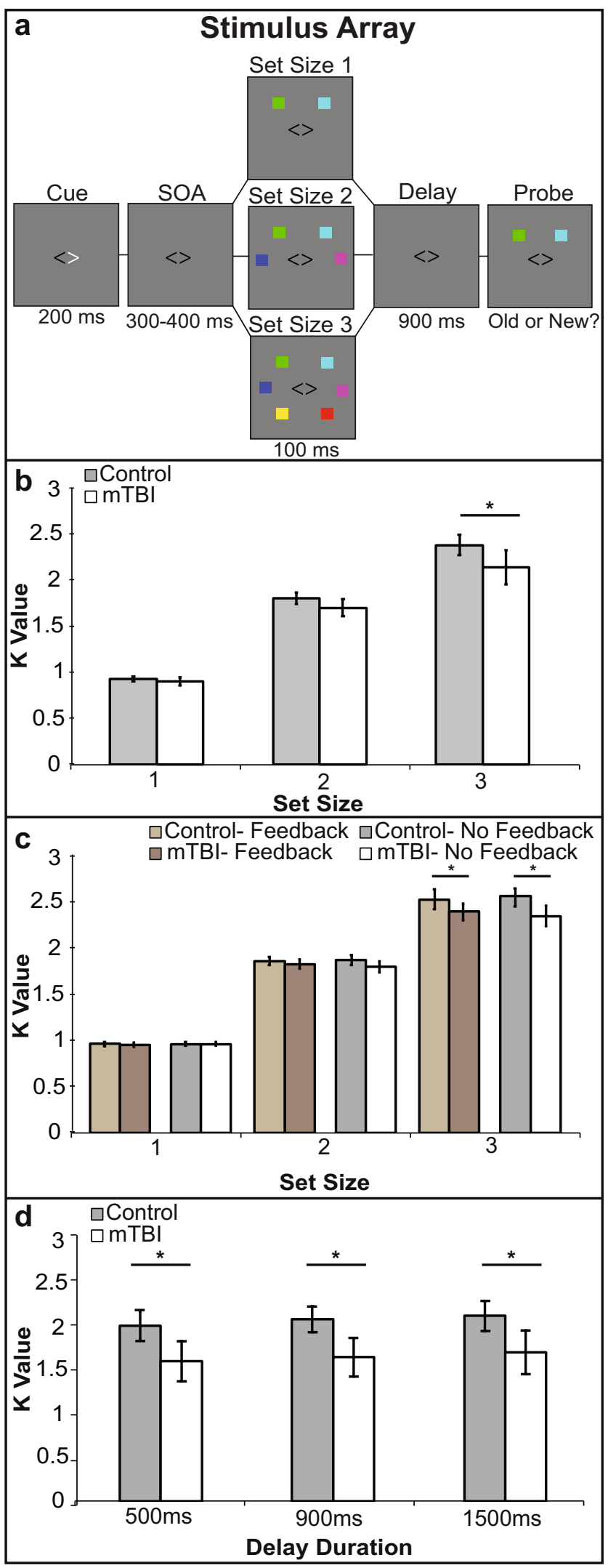

Fig. 1 Task paradigm, stimulus configurations, and behavioral results for Experiments 1-3. (a) Trial sequence. (b) Experiment 1: A Group $\times$ Set Size interaction emerges at set size 3. (c) Experiment 2: A replication of the Set Size $\times$ Group interaction, for which feedback made no difference. (d) Experiment 3: The mTBI group is impaired across maintenance delays at set size 3 . Error bars indicate $95 \%$ confidence intervals

\section{Combined Experiment 1-3 analyses}

To begin to parse the main effect of group, we ran a multiple regression across Experiments 1-3, inputting the $K$ values for the single condition included across all experiments (set size 3, 900-ms delay condition), to test whether number of mTBIs and time since last mTBI could predict WM performance ( $K$ value). However, no significant relationship was identified $\left[F(2,63)=1.04, p=.36, R^{2}=.03\right]$, and neither the number of TBIs nor the time since injury significantly predicted WM performance $(p s>.77)$.

\section{Experiment 4}

Increasing maintenance demands revealed no disproportionate deficit in the mTBI group, suggesting that WM maintenance cannot fully account for the group differences. We turned to retrieval demands, to test whether retrieval processing accounted for the mTBI deficit. We included recognition and recall probes in order to evaluate retrieval processing with new stimuli.

\section{Materials and method}

Participants New participants were recruited (see Table 1). Of these, 12 mTBI participants reported no LOC, whereas ten reported LOC $(M=6.41 \mathrm{~min}, S D=10.52$, range $=1 \mathrm{~s}-30$ $\mathrm{min})$. The mTBIs were all closed-head injuries: 12 sports-related, six falls/accidents, one fight, and three participants elected not to answer.

Procedure The stimuli were displayed on a 15 -in. MacBookPro. This task was previously described in detail (Gozenman, Tanoue, Metoyer, \& Berryhill, 2014). Several differences in the stimuli, set size, and task demands were implemented. Four oriented line segments $\left(7.5^{\circ} \times 1.5^{\circ}\right)$ appeared $6.5^{\circ}$ from fixation. Trials began with fixation $(1,500 \mathrm{~ms})$, which was followed by encoding (1,000 ms) and maintenance (900 ms). Recognition probes contained one item, and participants reported whether it matched the original orientation ("o" match, " $n$ " nonmatch, 50\% probabilities). Recall probes required rotation of the probe item (with the arrow keys, $1 \%$ keypress). Participants completed 200 trials per task in counterbalanced blocks; see Fig. 2a. Performance on recall trials was reflected by 


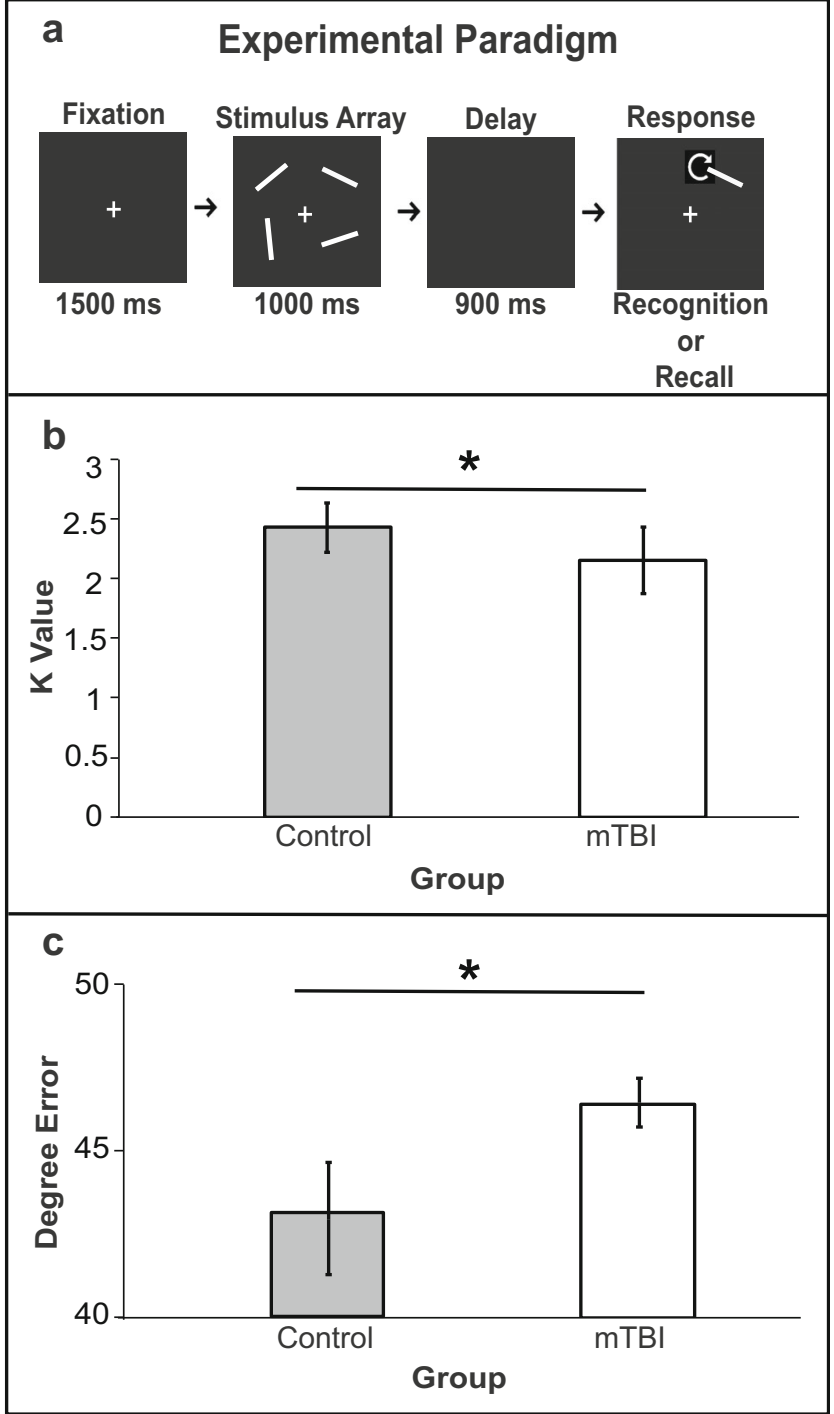

Fig. 2 Task paradigm, stimulus configurations, and behavioral results for Experiment 4. (a) Trial sequence for recognition and recall trials. (b) Recognition results. (c) Recall results. Both sets of results show impairment in the mTBI group. All error bars reflect $95 \%$ confidence intervals

degrees error. Participants performed an auditory suppression task throughout, to minimize verbal strategies.

\section{Results}

Significant group differences for each retrieval task revealed mTBI impairments [recognition $K, t(21)=2.21, p=.03$; recognition reaction time, $t(21)=-1.96, p=.05$; recall error rates, $t(21)=-2.84, p=.006$ ]; see Fig. $2 \mathrm{~b}$, c. Recall reaction times were not measured, because multiple button presses were required.

To evaluate the interaction across probes using different performance metrics, we converted the recognition and recall performance of the mTBI group into $z$ scores and subtracted them $\left(z_{\text {Recall }}-z_{\text {Recog }}\right)$. A one-sample $t$ test using a test value of
0 revealed no significant difference $[t(21)=0.30, p=.78]$, indicating the absence of an interaction across retrieval tasks.

\section{Discussion}

Few studies have investigated the chronic mTBI population, despite its large size and despite evidence that the consequences of mTBI can be long-lasting (Hou et al., 2012; Kenzie et al., 2017; Moser \& Schatz, 2002; Stockbridge, 2018). The present participants reported no residual symptoms of mTBI, despite having a history of mTBI. In this population, our data revealed that four different samples of undergraduates with a history of mTBI had WM impairments. Notably, the mean time since injury was measured in years, not weeks or months. Thus, even in active, otherwise healthy undergraduates, traces of mTBI remain.

A history of mTBI appears to be detrimental to WM. Specifically, the WM deficit reliably emerged at a set size of 3 , suggesting that encoding for one or two items was adequate. Feedback did not rescue mTBI performance, although a financial incentive might have been more compelling (Jones, Gozenman, \& Berryhill, 2015). WM maintenance failures cannot account for the mTBI deficit, because lengthening maintenance did not increase WM deficits. Manipulating the retrieval demands did not identify a disproportionate WM deficit in the mTBI group. We also identified a deficit in the mTBI group using an encoding duration ten times longer than that used in Experiments 1-3. The nature of this deficit remains unclear, likely due to the heterogeneity of mTBI. We are left without a clear attribution to a particular stage of WM (e.g., encoding, maintenance, or retrieval). Thus, despite a reliable performance difference in such a heterogeneous population, the nature of the WM deficits emerges across multiple stages of WM, and potentially differently across participants. Having identified a reliable difference in our undergraduate population, we may now probe these questions more carefully going forward.

\section{Limitations}

We wanted to understand whether some of the low WM performance in our laboratory studies could be due to a history of mTBI, since a high number of our participants report having had one or more of these. It seems unlikely that a participant would deliberately mislead us, given the option of participating as a control. We made no attempt to restrict participation, and we relied on self-reports of mTBI. We also recruited multiple cohorts of mTBI participants rather than more comprehensively probing a single cohort. We argue that recruiting multiple cohorts should increase the between-subjects noise and work against finding a consistent mTBI-specific deficit at the group level. Another limitation is that we only tested WM and did not test cognitive performance more broadly, or 
measure personality traits to see whether high risk-taking or impulsivity accounted for some of the difference. It seems quite unlikely that we stumbled on the only task that would reveal impairment. The present data indicate that unaddressed long-term consequences of mTBI persist in an otherwise successful population: enrolled undergraduates. Future efforts must carefully measure and weigh multivariate factors, including mTBI etiology, quality and compliance with medical advice, social support surrounding the injury, and so forth (Kenzie et al., 2017). We would benefit by more comprehensively testing one cohort in order to characterize the boundary between intact and impaired function in a within-participants fashion. These findings reveal the need for asking participants regarding their history of mTBI and suggests that it will be useful to develop restorative protocols across the mTBI survivor population, regardless of how highly functioning they are or how long since their injury.

Author note Funding was provided from the University of Nevada, Reno, Office of Undergraduate Research (to A.K.-G., J.M.), NSF Grants OIA 1632849 and OIA 1632738 (M.E.B.), NIGMS Grant P20GM103650 (M.E.B.), and the Tahoe Institute for Rural Health Research (M.E.B.). The content is solely the responsibility of the authors and does not represent the official views of any funding agency. The authors declare they have no conflicts of interest.

\section{References}

Adam, K. C. S., \& Vogel, E. K. (2017). Confident failures: Lapses of working memory reveal a metacognitive blind spot. Attention, Perception, \& Psychophysics, 79, 1506-1523. https://doi.org/10. 3758/s13414-017-1331-8

Bajaj, S., Dailey, N. S., Rosso, I. M., Rauch, S. L., \& Killgore, W. D. S. (2018). Time-dependent differences in cortical measures and their associations with behavioral measures following mild traumatic brain injury. Human Brain Mapping, 39, 1886-1897. https://doi. org $/ 10.1002 / \mathrm{hbm} .23951$

Bazarian, J. J., McClung, J., Shah, M. N., Cheng, Y. T., Flesher, W., \& Kraus, J. (2005). Mild traumatic brain injury in the United States, 1998-2000. Brain Injury, 19, 85-91. https://doi.org/10.1080/ 02699050410001720158

Belanger, H. G., \& Vanderploeg, R. D. (2005). The neuropsychological impact of sports-related concussion: A meta-analysis. Journal of the International Neuropsychological Society, 11, 345-357.

Brainard, D. H. (1997). The Psychophysics Toolbox. Spatial Vision, 10, 433-436. https://doi.org/10.1163/156856897X00357

Cameron, K. L., Marshall, S. W., Sturdivant, R. X., \& Lincoln, A. E. (2012). Trends in the incidence of physician-diagnosed mild traumatic brain injury among active duty U.S. military personnel between 1997 and 2007. Journal of Neurotrauma, 29, 1313-1321. https://doi.org/10.1089/neu.2011.2168

Catale, C., Marique, P., Closset, A., \& Meulemans, T. (2008). Attentional and executive functioning following mild traumatic brain injury in children using the Test for Attentional Performance (TAP) battery. Journal of Clinical and Experimental Neuropsychology, 31, 331338. https://doi.org/10.1080/13803390802134616

Cooper, D. B., Bunner, A. E., Kennedy, J. E., Balldin, V., Tate, D. F., Eapen, B. C., \& Jaramillo, C. A. (2015). Treatment of persistent post-concussive symptoms after mild traumatic brain injury: A systematic review of cognitive rehabilitation and behavioral health interventions in military service members and veterans. Brain Imaging and Behavior, 9, 403-420. https://doi.org/10.1007/ s11682-015-9440-2

Corrigan, J. D., Selassie, A. W., \& Orman, J. A. L. (2010). The epidemiology of traumatic brain injury. Journal of Head Trauma Rehabilitation, 25, 72-80. https://doi.org/10.1097/HTR. 0b013e3181ccc8b4

Cowan, N. (2001). The magical number 4 in short-term memory: A reconsideration of mental storage capacity. Behavioral and Brain Sciences, 24,87-185.https://doi.org/10.1017/ S0140525X01003922

Dall'Acqua, P., Johannes, S., Mica, L., Simmen, H. P., Glaab, R., Fandino, J., . . . Hanggi, J. (2017). Prefrontal cortical thickening after mild traumatic brain injury: A one-year magnetic resonance imaging study. Journal of Neurotrauma, 34, 3270-3279. https:// doi.org/10.1089/neu.2017.5124

De Monte, V. E., \& Geffen, G. M. (2005). Effects of mild traumatic brain injury: Comparison of direct and indirect injury groups. Brain Impairment, 6, 109-116. https://doi.org/10.1375/brim.2005.6.2.109

Dean, P. J., \& Sterr, A. (2013). Long-term effects of mild traumatic brain injury on cognitive performance. Frontiers in Human Neuroscience, 7, 30. https://doi.org/10.3389/fnhum.2013.00030

Eierud, C., Craddock, R. C., Fletcher, S., Aulakh, M., King-Casas, B., Kuehl, D., \& LaConte, S. M. (2014). Neuroimaging after mild traumatic brain injury: Review and meta-analysis. NeuroImage: Clinical, 4, 283-294. https://doi.org/10.1016/j.nicl.2013.12.009

Faul, M., Xu, L., Wald, M. M., \& Coronado, V. G. (2010). Traumatic brain injury in the United States: Emergency department visits, hospitalizations and deaths 2002-2006 (CDC blue book). Atlanta, GA: Centers for Disease Control and Prevention.

Fino, P. C., Parrington, L., Walls, M., Sippel, E., Hullar, T. E., Chesnutt, J. C., \& King, L. A. (2018). Abnormal turning and its association with self-reported symptoms in chronic mild traumatic brain injury. Journal of Neurotrauma, 35, 1167-1177. https://doi.org/10.1089/ neu.2017.5231

Fukuda, K., Awh, E., \& Vogel, E. K. (2010). Discrete capacity limits in visual working memory. Current Opinion in Neurobiology, 20, 177 182. https://doi.org/10.1016/j.conb.2010.03.005

Goetzl, E. J., Elahi, F. M., Mustapic, M., Kapogiannis, D., Pryhoda, M., Gilmore, A., . . . Ledreux, A. (2019). Altered levels of plasma neuron-derived exosomes and their cargo proteins characterize acute and chronic mild traumatic brain injury. FASEB Journal, 33, 50825088. https://doi.org/10.1096/fj.201802319R

Gosselin, N., Bottari, C., Chen, J. K., Huntgeburth, S. C., De Beaumont, L., Petrides, M., ... Ptito, A. (2012). Evaluating the cognitive consequences of mild traumatic brain injury and concussion by using electrophysiology. Neurosurgical Focus, 33, E7:1-7. https://doi.org/ 10.3171/2012.10.FOCUS12253

Gozenman, F., Tanoue, R. T., Metoyer, T., \& Berryhill, M. E. (2014). Invalid retro-cues can eliminate the retro-cue benefit: Evidence for a hybridized account. Journal of Experimental Psychology: Human Perception and Performance, 40, 1748-1754. https://doi.org/10. 1037/a0037474

Ham, T. E., Bonnelle, V., Hellyer, P., Jilka, S., Robertson, I. H., Leech, R., \& Sharp, D. J. (2014). The neural basis of impaired self-awareness after traumatic brain injury. Brain, 137, 586-597. https://doi.org/10. 1093/brain/awt350

Hou, R., Moss-Morris, R., Peveler, R., Mogg, K., Bradley, B. P., \& Belli, A. (2012). When a minor head injury results in enduring symptoms: A prospective investigation of risk factors for postconcussional syndrome after mild traumatic brain injury. Journal of Neurology, Neurosurgery \& Psychiatry, 83, 217-223. https://doi.org/10.1136/ jnnp-2011-300767

Hudac, C. M., Cortesa, C. S., Ledwidge, P. S., \& Molfese, D. L. (2018). History of concussion impacts electrophysiological correlates of 
working memory. International Journal of Psychophysiology, 132, 135-144. https://doi.org/10.1016/j.ijpsycho.2017.09.020

Ikkai, A., McCollough, A. W., \& Vogel, E. K. (2010). Contralateral delay activity provides a neural measure of the number of representations in visual working memory. Journal of Neurophysiology, 103, 1963 1968. https://doi.org/10.1152/jn.00978.2009

Jones, K. T., Gozenman, F., \& Berryhill, M. E. (2015). The strategy and motivational influences on the beneficial effect of neurostimulation: A tDCS and fNIRS study. NeuroImage, 105, 238-247. https://doi. org/10.1016/j.neuroimage.2014.11.012

Kenzie, E. S., Parks, E. L., Bigler, E. D., Lim, M. M., Chesnutt, J. C., \& Wakeland, W. (2017). Concussion as a multi-scale complex system: An interdisciplinary synthesis of present knowledge. Frontiers in Neurology, 8, 513. https://doi.org/10.3389/fneur.2017.00513

Konrad, C., Geburek, A. J., Rist, F., Blumenroth, H., Fischer, B., Husstedt, I., . . . Lohmann, H. (2011). Long-term cognitive and emotional consequences of mild traumatic brain injury. Psychological Medicine, 41, 1197-1211. https://doi.org/10.1017/ S0033291710001728

Larrabee, G. J. (2012). Mild traumatic brain injury. In G. J. Larrabee (Ed.), Forensic neuropsychology: A scientific approach (pp. 231259). New York, NY, US: Oxford University Press.

Lotan, E., Morley, C., Newman, J., Qian, M., Abu-Amara, D., Marmar, C., \& Lui, Y. W. (2018). Prevalence of cerebral microhemorrhage following chronic blast-related mild traumatic brain injury in military service members using susceptibility-weighted MRI. American Journal of Neuroradiology, 39, 1222-1225. https://doi.org/10.3174/ ajnr.A5688

Luck, S. J., \& Vogel, E. K. (2013). Visual working memory capacity: From psychophysics and neurobiology to individual differences. Trends in Cognitive Sciences, 17, 391-400. https://doi.org/10. 1016/j.tics.2013.06.006

Luria, R., Balaban, H., Awh, E., \& Vogel, E. K. (2016). The contralateral delay activity as a neural measure of visual working memory. Neuroscience and Biobehavioral Reviews, 62, 100-108. https:// doi.org/10.1016/j.neubiorev.2016.01.003

Mayer, A. R., Yang, Z., Yeo, R. A., Pena, A., Ling, J. M., Mannell, M. V., . . Mojtahed, K. (2012). A functional MRI study of multimodal selective attention following mild traumatic brain injury. Brain Imaging and Behavior, 6, 343-354. https://doi.org/10.1007/ s11682-012-9178-z

McCollough, A. W., Machizawa, M. G., \& Vogel, E. K. (2007). Electrophysiological measures of maintaining representations in visual working memory. Cortex, 43, 77-94. https://doi.org/10.1016/ S0010-9452(08)70447-7

McInnes, K., Friesen, C. L., MacKenzie, D. E., Westwood, D. A., \& Boe, S. G. (2017). Mild Traumatic Brain Injury (mTBI) and chronic cognitive impairment: A scoping review. PLoS ONE, 12, e0174847. https://doi.org/10.1371/journal.pone.0174847

McNerney, M. W., Hobday, T., Cole, B., Ganong, R., Winans, N., Matthews, D., . . . Lane, S. (2019). Objective classification of mTBI using machine learning on a combination of frontopolar electroencephalography measurements and self-reported symptoms. Sports Medicine Open, 5, 14. https://doi.org/10.1186/s40798-0190187-y

Miranda, A. T., \& Palmer, E. M. (2014). Intrinsic motivation and attentional capture from gamelike features in a visual search task. Behavior Research Methods, 46, 159-172. https://doi.org/10.3758/ s13428-013-0357-7

Moser, R. S., \& Schatz, P. (2002). Enduring effects of concussion in youth athletes. Archives of Clinical Neuropsychology, 17, 91-100. https:// doi.org/10.1016/S0887-6177(01)00108-1
Pan, J., Connolly, I. D., Dangelmajer, S., Kintzing, J., Ho, A. L., \& Grant, G. (2016). Sports-related brain injuries: Connecting pathology to diagnosis. Neurosurgical Focus, 40, E14. https://doi.org/10.3171/ 2016.1.FOCUS15607

Pashler, H. (1988). Familiarity and visual change detection. Perception \& Psychophysics, 44, 369-378. https://doi.org/10.3758/BF03210419

Pelli, D. G. (1997). The VideoToolbox software for visual psychophysics: Transforming numbers into movies. Spatial Vision, 10, 437-442. https://doi.org/10.1163/156856897X00366

Ransom, D. M., Burns, A. R., Youngstrom, E. A., Vaughan, C. G., Sady, M. D., \& Gioia, G. A. (2016). Applying an evidence-based assessment model to identify students at risk for perceived academic problems following concussion. Journal of the International Neuropsychological Society, 22, 1038-1049. https://doi.org/10. 1017/S1355617716000916

Sharp, D. J., \& Ham, T. E. (2011). Investigating white matter injury after mild traumatic brain injury. Current Opinion in Neurology, 24, 558563. https://doi.org/10.1097/WCO.0b013e32834cd523

Sharp, D. J., Scott, G., \& Leech, R. (2014). Network dysfunction after traumatic brain injury. Nature Reviews Neurology, 10, 156-166. https://doi.org/10.1038/nrneurol.2014.15

Shenton, M. E., Hamoda, H. M., Schneiderman, J. S., Bouix, S., Pasternak, O., Rathi, Y., . . . Zafonte, R. (2012). A review of magnetic resonance imaging and diffusion tensor imaging findings in mild traumatic brain injury. Brain Imaging and Behavior, 6, 137192. https://doi.org/10.1007/s11682-012-9156-5

Shumskaya, E., Andriessen, T. M. J. C., Norris, D. G., \& Vos, P. E. (2012). Abnormal whole-brain functional networks in homogeneous acute mild traumatic brain injury. Neurology, 79, 175-182. https://doi.org/10.1212/WNL.0b013e31825f04fb

Stockbridge, M. D. (2018). The role of personality and cognitivelinguistic deficits in teens and adults with concussion (Doctoral dissertation, University of Maryland). Retrieved from ProQuest, Dissertations \& Theses Global

Tate, D. F., Shenton, M. E., \& Bigler, E. D. (2012). Introduction to the brain imaging and behavior special issue on neuroimaging findings in mild traumatic brain injury. Brain Imaging and Behavior, 6, 103 107. https://doi.org/10.1007/s11682-012-9185-0

Taylor, C. A., Greenspan, A. I., Xu, L., \& Kresnow, M.-J. (2015). Comparability of national estimates for traumatic brain injuryrelated medical encounters. Journal of Head Trauma Rehabilitation, 30, 150-159. https://doi.org/10.1097/HTR. 0000000000000105

Vanderploeg, R. D., Curtiss, G., \& Belanger, H. G. (2005). Long-term neuropsychological outcomes following mild traumatic brain injury. Journal of the International Neuropsychological Society, 11, 228236. https://doi.org/10.1017/S1355617705050289

Vogel, E. K., \& Machizawa, M. G. (2004). Neural activity predicts individual differences in visual working memory capacity. Nature, 428 , 748-751. https://doi.org/10.1038/nature02447

Wammes, J. D., Good, T. J., \& Fernandes, M. A. (2017). Autobiographical and episodic memory deficits in mild traumatic brain injury. Brain and Cognition, 111, 112-126. https://doi.org/10. 1016/j.bandc.2016.11.004

Publisher's note Springer Nature remains neutral with regard to jurisdictional claims in published maps and institutional affiliations. 